\title{
Exploring the attitudes and experiences of adolescents with type 1 diabetes towards transition of care
}

\author{
Saskia D'Sa ${ }^{1}$ (D) - Deirdre J. Foley ${ }^{1} \cdot$ Kerrie Hennigan ${ }^{1} \cdot$ Maria Kelly-Conroy $^{1} \cdot$ Anne Quinn $^{1} \cdot$ Mary Norris ${ }^{1}$. \\ Therese Dunne $^{1}$ - Yvonne Moloney ${ }^{2,3}$. Sarah Fitzpatrick ${ }^{2}$ - Eoin Noctor ${ }^{2,4}$ - Orla M. Neylon ${ }^{1,4}$ - C. S. O'Gorman ${ }^{1,4}$
}

Received: 16 January 2021 / Accepted: 22 June 2021

(C) The Author(s) 2021

\begin{abstract}
Introduction Transition from adolescence to adult care is very challenging for most patients. Without appropriate appointments and education, adolescents can get lost to follow up within one-year of transitioning to adult care (Mistry et al. Diabet Med 32(7):881-885, 2015). Loss to follow-up can increase risks of adverse short and long term diabetes-related complications, with healthcare contacts mainly limited to crisis-based management (Iversen et al. Scand J Caring Sci 33(3):723-730, 2019).

Aims The purpose of this study was to evaluate the patient's perspective of the process of transition from paediatric to adult-based diabetes services in the Mid-West Region of Ireland.

Methods We implemented a new transition clinic at University Hospital Limerick with the collaboration of paediatric and adult endocrinology teams. Eighteen patients opted to attend the clinic, but only 17 patients consented to participate in a qualitative assessment study and completed questionnaires before and after the transition clinic.

Results and conclusion In terms of medical management, patients had a good understanding of hypoglycaemia and insulin dose adjustment principles, but were least comfortable with carbohydrate counting. Patients self-ranked their knowledge on driving and sexual health with a diagnosis of diabetes as poor, in comparison to understanding effects of alcohol and smoking on diabetes. Overall, a majority of the respondents felt more confident in moving to adult-care after attending the transition clinic.
\end{abstract}

Keywords Transition $\cdot$ Type 1 diabetes $\cdot$ Clinics $\cdot$ Adolescence

\section{Introduction}

There are approximately 20,000 patients with type 1 diabetes mellitus (T1DM) in Ireland. This accounts for $10-15 \%$ of the total Irish population living with diabetes (Diabetes Ireland 2020). Of this number, 2750 are children under the age of 16 years (Diabetes Ireland 2020). Diabetes is a chronic illness requiring thorough monitoring and outpatient follow-up.

Saskia D'Sa

saskia.dsa@gmail.com

1 Department of Paediatrics, University Hospital Limerick (UHL), Limerick, Ireland

2 Department of Endocrinology, University Hospital Limerick (UHL), Limerick, Ireland

3 University Maternity Hospital Limerick (UHML), Limerick, Ireland

4 Graduate Entry Medical School (GEMS), University of Limerick, Limerick, Ireland
Optimal glycemic control early in life mitigates the risks of long-term complications of hyperglycemia (Shulman et al. 2019). In paediatrics, diabetes care is family-oriented, relying on a strong relationship between the patient, family and the multidisciplinary paediatric diabetes team (Monaghan and Baumann 2016). In adult medicine, waiting times are often longer by comparison, with appointments themselves usually shorter than those of paediatric sessions and typically lesser involvement from multidisciplinary teams with services specifically supporting behavioural health (Monaghan and Baumann 2016).

The transition period from adolescence to adulthood can be challenging psychologically, physically and socially (Iyengar et al. 2019; Pyatak et al. 2014; Shulman et al. 2018). It is a crucial time that often can dictate the future management of this chronic illness (Campbell et al. 2016). Particular attention should be drawn to young adults from ethnic minorities who are considered at increased risk of poor transition outcomes (Lotstein et al. 2013). Effective management of diabetes can be challenging for adolescents transitioning to adult services. 
This may be due to the burden of independent management of the illness with emphasis on diet, self monitoring, administration of insulin and attendance at medical follow-up appointments. At this point, there can be an increased risk of break in the continuity of care, and close involvement of allied health practitioners in the management of chronic illnesses (Campbell et al. 2016). In this context, it is possible that transition clinics might facilitate the transition of diabetes care from paediatrics to young adulthood.

Optimal transition of care should be a gradual process taking place over a time period of months to years, with tailored clinic services linking paediatric and adult multi-disciplinary teams with the patient (Campbell et al. 2016; Pyatak et al. 2014). The goals of these clinics rely heavily on open lines of communication between providers, professionals, families and patients (Campbell et al. 2016). During these transition clinics, the paediatric diabetes team identifies the strengths and weaknesses within the care of each transitioning patient, and addresses their psychosocial concerns (Shulman et al. 2019). It has been shown that adolescents with complicated health histories and lower levels of education are more likely to be at risk of poorer medical outcomes following transfer to adult care (Alassaf et al. 2017). Therefore, this team-based transition approach is crucial to keep patients engaged, build rapport and support the adult care teams in prioritizing the most vulnerable patients (Shulman et al. 2019). Ultimately, teams aim to work towards the goal of ensuring a minimally interrupted process of health care delivery between the paediatric and adult care settings (White et al. 2015).

\section{Aims}

The purpose of this study was to explore the attitudes and experiences of adolescents attending a transition clinic during the transition process at diabetes services in Mid-West Ireland, through a specialised clinic bridging transfer from paediatric to adult care.

\section{Methods}

Transition clinics were run annually at University Hospital Limerick (UHL) over a 2-year period for adolescents with T1DM moving from paediatric to adult services. Ethical approval was obtained prior to commencement of this study and informed consent was taken from all participants.

The clinic was staffed by members of both the paediatric and adult diabetes teams. This included 1-2 paediatric endocrinology consultants, two non-consultant hospital doctors, three paediatric diabetes specialist nurses, one paediatric-trained medical social worker and one paediatric dietician. Representatives from the adult diabetes service included one endocrinology consultant, one diabetes nurse, one diabetes advanced midwife practitioner and one podiatrist (where possible). There were no non-consultant hospital doctors (NCHDs), social workers or dieticians present from the adult service. Initially, 21 patients, aged 16 to 19 -years old were invited to attend the clinic. Of this cohort, one patient did not attend, and two patients cancelled. Although 18 patients attended the clinic, only 17 of them completed our questionnaires.

Patients attending were given a questionnaire compiled by the Paediatric endocrinology consultants at UHL. Eighteen patients were given questionnaires, out of which 17 patients completed it. The questionnaire consisted of 28 questions in total, ranging from objective measurements (i.e. $\mathrm{HbAlc}$ ) and subjective experiences (i.e. knowledge of carbohydrate counting, driving, alcohol). The patients initially met the paediatric nurses, and objective data such as anthropometry, blood glucose level, point-of-care $\mathrm{HbAlc}$ and urine were tested. The objective measurements were provided to patients and their subjective attitudes, behaviours and concerns were assessed in the questionnaire. Each questionnaire was completed by the patient independently via 'yes' or 'no' answers, followed by a free text option to elaborate further. A pre- and post-clinic survey was distributed to address the concerns before and their attitudes after. Each patient's appointment lasted $30 \mathrm{~min}$ in total. The pilot questionnaire was trialled in advance on young people transitioning to adult services, and the final questionnaire was refined based on their feedback and these responses were not included in this study.

The questionnaire aimed to collect data on each young person with T1DM regarding medical and social readiness and the qualitative experience of attending the transition clinic. We evaluated the data placing particular emphasis on the qualitative results provided in the patient questionnaires. Data were extracted from the completed questionnaires and collated with Excel. Data were analysed using supporting statistics and summarized into graphs to highlight the qualitative answers that were given by the patients post-completion of the clinic. The categories evaluated were further separated based on the medical and social management of diabetes and the effectiveness of the transition clinics.

\section{Results}

Seventeen $(94 \%, n=17)$ patients in total completed the questionnaire, of which 12 were female and five were male. The participants ranged from 16 to 19 years old, and the mean $\mathrm{HbAlc}$ was $9.1 \%$ (11.7 mmol/L).

Prior to attending the clinic, the patients shared their expectations and concerns for their clinic appointment. The patients had expectations that were summarized as the following: 'transitioning smoothly', 'better HbAlc regulation' and 'learning about transfer of care to the adult team'. Concerns 
documented by the patients were summarized as the following: 'adequate HbA1c levels', 'moving to adult care' and concerns regarding appointments being 'crowded, delayed and unknown [not knowing]'.

In terms of the medical management of diabetes, there was a wide variation of $\mathrm{HbA} 1 \mathrm{c}$ levels recorded ranging from $6.7 \%$ $(8.1 \mathrm{mmol} / \mathrm{L})$ to $14 \%(19.6 \mathrm{mmol} / \mathrm{L})$, with the mean as $9.1 \%$ (Fig. 1). Upon further analysis of the data, the majority of attendees felt adequately skilled in their ability to adjust insulin and manage hypoglycaemic episodes, whereas a smaller number of patients felt confident in carbohydrate counting (Fig. 2).

\section{Education for insulin dose adjustment and carbohydrate counting}

With respect to the social aspect associated with diabetes, patients felt most comfortable with their knowledge of alcohol and smoking management. However, only 14 (82\%) attendees felt comfortable with their education regarding sexual health, and only $12(71 \%)$ attendees felt comfortable with their education and understanding of the effects of driving and diabetes (Fig. 3).

\section{Post-clinic questionnaire}

The patients were also given the opportunity to complete a questionnaire at the end of their transition clinic appointment. Ten $(56 \%)$ responders felt more confident after the clinic visit that they would be comfortable transitioning to adult diabetes care, whereas seven (44\%) responders felt the same as they did prior to the appointment. Seventeen $(100 \%)$ responders however, found the clinic to be helpful with the transition process (Fig. 4). When asked to elaborate, adolescents were 'happy to meet' the health care practitioners (HCPs). One mentioned that it was 'easy to talk to as they were nice and accessible'. Multiple patients expressed that the team was 'helpful, friendly' and were given 'lots of opportunities to ask questions... [and HCPs] answered all questions'. Lastly,

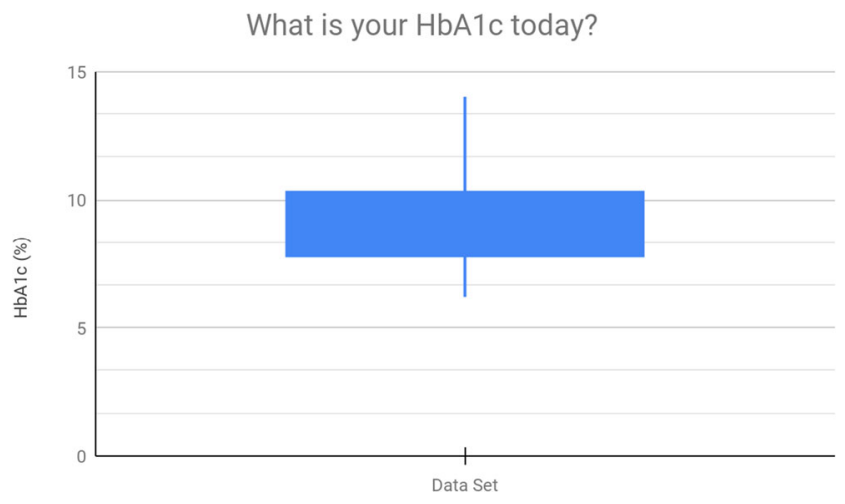

Fig. 1 Levels of HbAlc (\%) distribution amongst attendees one of the adolescents described that they 'now know everyone's names and what to expect from them which is helpful in transition'.

\section{Discussion}

This study demonstrated that transition clinics provide a 'safe space' for adolescents to meet with their adult team and ask any concerning questions. Having at least $56 \%$ of patients feeling more confident or as confident in moving to adult diabetes care shows the importance in facilitating these clinics. However, follow-up steps of establishing baseline confidence levels prior to the clinic could help in understanding the level of improvement between the parameters. From this study, we recognize areas in which education could be optimized, for example, carbohydrate counting, driving and sexual health, and propose a follow-up need for structured transition programmes. These programmes can contribute to young adults with T1DM receiving a personalized, safe and positive transition at an otherwise demanding phase of life (Iversen et al. 2019).

We found in our study that most individuals self-reported confidence in issues such as insulin dose adjusting and hypoglycaemia management. According to the American Diabetes Association (ADA), adolescents and young adults between the ages of 13 to 19 should aim for a target $\mathrm{HbAlc}$ of $<7.5 \%$ (ADA 2012). However, our data noted a suboptimal $\mathrm{HbA1c}$ with medical management suggesting that there may be some level of reporting due to overconfidence. Furthermore, we acknowledge that more focus certainly is needed on educating patients on carbohydrate counting. Owing to the increased responsibility placed on patients in adult-care, it is essential to conduct focused educational sessions for improving knowledge and concerns with the highlighted management of T1DM. It is noteworthy that education on all of these issues was provided to clinic attendees both while in the paediatrics service and during the transition clinic, the latter in response to the adolescents' perceived deficiencies in their own education. However this study measured their perception of their knowledge and changes do need to be made so that in future, young people are confident in their knowledge by the time of their transition.

The data on perceived readiness with respect to social issues highlighted the need for increased attention towards driving and sexual health. Having only $71 \%$ of our adolescent cohort feeling satisfied with their knowledge on driving with T1DM is concerning at both a personal and societal level. This is an area in which we can improve our education aimed at the adolescent cohort. Monaghan and Baumann (2016) recognizes that the adult-care services can typically have greater emphasis on objective rather than subjective measurements (Monaghan and Baumann 2016). Hence, recognizing these 
Fig. 2 Qualitative readiness of the medical management associated with diabetes
Do you feel that you have adequate hypoglycemia management education?

$$
94 \%
$$

Do you feel that you have adequate insulin dose adjustment management?

$$
94 \%
$$

Do you feel that you have adequate carbohydrate counting management?

\begin{tabular}{|l|l}
\hline $82 \%$ & $18 \%$ \\
\hline
\end{tabular}

Yes $\quad$ No social issues are important to address prior to the transitioning to adult care.

Our results display that transition clinics are essential in helping adolescents feel more prepared to enter into the network of adult diabetes care. We note from the freetext data that patients had significant concerns such as crowding and delays in adult care. Understanding the concerns and needs of adolescent patients differing from those of younger children can help direct attention towards these issues (Mulvaney et al. 2010). Pyatak et al. [2014] noted that psychosocial stressors among young adults with T1DM with low socio-economic status are more common
Fig. 3 Qualitative readiness of the social management associated with diabetes

\section{Graph 1: Adequate education on safe use of alcohol}

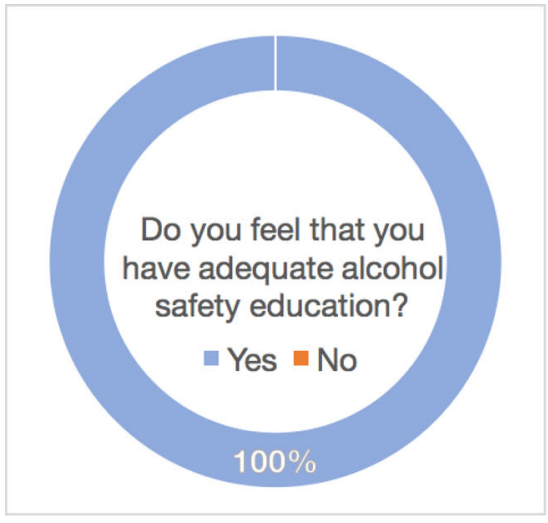

Graph 3: Adequate education on safe use of sexual health

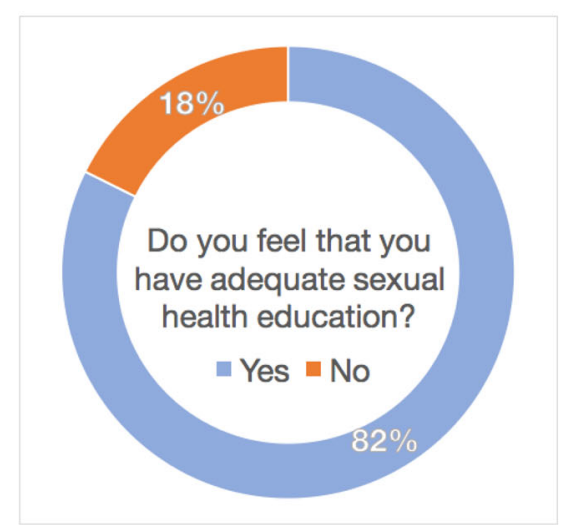

Graph 2: Adequate education on safe use of driving

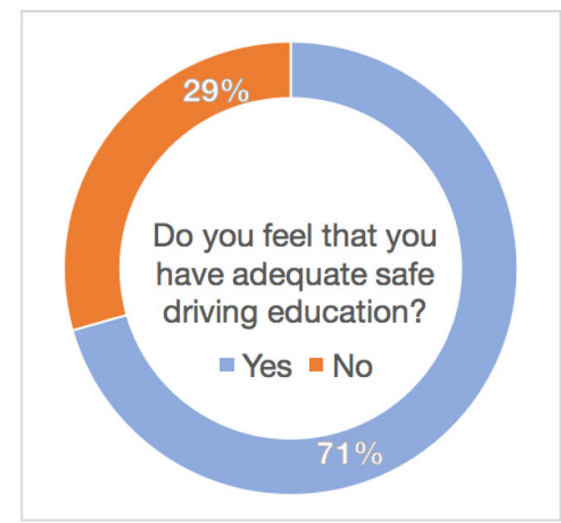

Graph 4: Adequate education on safe use of smoking

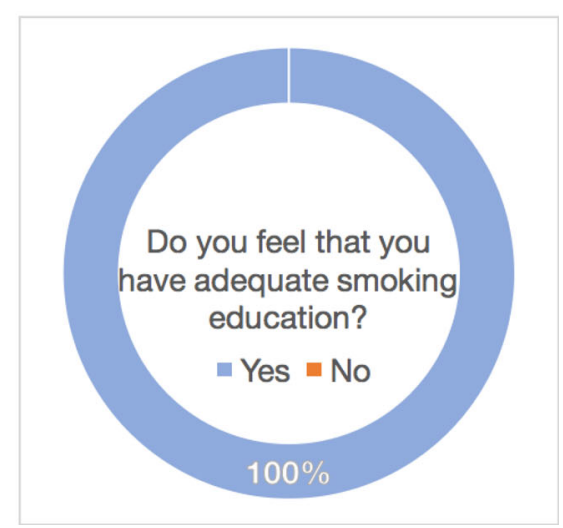


Fig. 4 Qualitative effectiveness of transition clinics amidst clinic attendees

\section{Graph 1 Level of confidence post transition clinic}

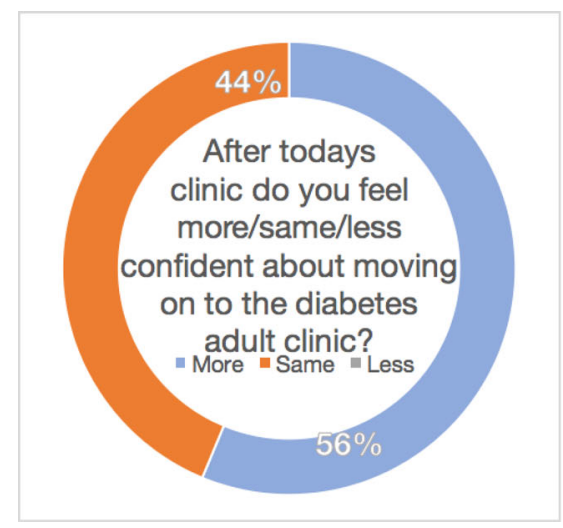

\section{Graph 2 Effectiveness of transition clinic}

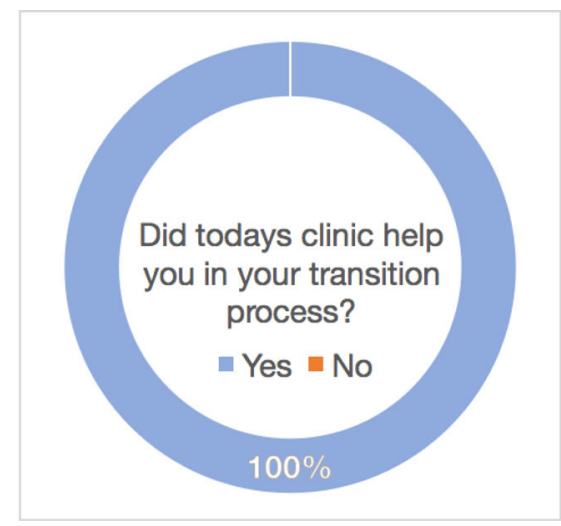

in adolescents from ethnic minority backgrounds. Identifying and providing resources to manage such stressors in the course of routine paediatric care may be crucial for maintaining ongoing follow-up and successful transition to adult care (Pyatak et al. 2014). Ultimately, transition clinics highlight any patients that might require a longer transition overlap between the paediatric and adult care, so to prevent anyone getting lost to follow up within the one-year transition to adult care (Mistry et al. 2015).

\section{Conclusions}

The goal of transition clinics are to prepare adolescents with T1DM for the changes associated in moving to adult-care. They are designed to identify an adolescents' readiness to manage social and medical issues, and to highlight those that need additional attention and education. Adequate knowledge and confidence in that knowledge, as well as awareness in self limitations and the initiative to reach out for help to adult services, are all key factors in young people who are developing towards self-management, advocacy and health literacy. This study has demonstrated the need for structured education in advance of transition, in partnership between the adolescent patients, their families and the paediatric and adult diabetes services. We acknowledge limitations in the study such as the smaller sample size which does leave space for bias amongst the attendees. We also noted the suboptimal HbAlc measurements, which would be important to compare between transition clinic attendees and non-attendees. Therefore, further studies will be required both to establish if the engagement with adult services is improved in young adults who have attended a structured multidisciplinary transition clinic and also in young people who, in future, attend for structured adolescent education in advance of transitioning to adult services.
Authors' contributions All authors' names on the manuscript have made contributions to the study conception and design.

Funding Open Access funding provided by the IReL Consortium. The authors did not obtain any external or additional funding in completion of the project.

Availability of data and materials Not applicable.

Code availability Not applicable.

\section{Declarations}

Ethical approval for this study was obtained from the Quality and Staff officer at University Limerick Hospitals Group.

Consent to participate Informed consent was obtained from all individual participants included in the study.

\section{Consent to publish Not applicable.}

Conflict of interest The authors declare that they have no conflict of interest.

Open Access This article is licensed under a Creative Commons Attribution 4.0 International License, which permits use, sharing, adaptation, distribution and reproduction in any medium or format, as long as you give appropriate credit to the original author(s) and the source, provide a link to the Creative Commons licence, and indicate if changes were made. The images or other third party material in this article are included in the article's Creative Commons licence, unless indicated otherwise in a credit line to the material. If material is not included in the article's Creative Commons licence and your intended use is not permitted by statutory regulation or exceeds the permitted use, you will need to obtain permission directly from the copyright holder. To view a copy of this licence, visit http://creativecommons.org/licenses/by/4.0/.

\section{References}

Alassaf A, Gharaibeh L, Grant C, Punthakee Z (2017) Predictors of type 1 diabetes mellitus outcomes in young adults after transition from 
pediatric care. J Diabetes 9(12):1058-1064. https://doi.org/10.1111/ 1753-0407.12536

American Diabetes Association (2012) Standards of medical care in diabetes-2012. Diabetes care, 35 Suppl 1(Suppl 1):S11-S63 https:// doi.org/10.2337/dc12-s011

Campbell F, Biggs K, Aldiss SK et al (2016) Transition of care for adolescents from paediatric services to adult health services. Cochrane Database Syst Rev 4:CD009794. https://doi.org/10. 1002/14651858.CD009794.pub2

Diabetes Ireland 2020. Diabetes prevalence in Ireland. Accessed July 2020. https://www.diabetes.ie/about-us/diabetes-in-ireland/

Iversen E, Kolltveit BH, Hernar I, Mårtensson J, Haugstvedt A (2019) (2019). Transition from paediatric to adult care: a qualitative study of the experiences of young adults with type 1 diabetes. Scand J Caring Sci 33(3):723-730. https://doi.org/10.1111/scs.12668

Iyengar J, Thomas IH, Soleimanpour SA (2019) Transition from pediatric to adult care in emerging adults with type 1 diabetes: a blueprint for effective receivership. Clin Diabetes Endocrinol 5:3. https://doi.org/ 10.1186/s40842-019-0078-7

Lotstein DS, Seid M, Klingensmith G, Case D, Lawrence JM, Pihoker C, Dabelea D, Mayer-Davis EJ, Gilliam LK, Corathers S, Imperatore G, Dolan L, Anderson A, Bell RA, Waitzfelder B, SEARCH for Diabetes in Youth Study Group (2013) Transition from pediatric to adult care for youth diagnosed with type 1 diabetes in adolescence. Pediatrics 131(4):e1062-e1070. https://doi.org/10.1542/peds.20121450

Mistry B, Van Blyderveen S, Punthakee Z, Grant C (2015) Conditionrelated predictors of successful transition from paediatric to adult care among adolescents with type 1 diabetes. Diabet Med 32(7): 881-885. https://doi.org/10.1111/dme.12746
Monaghan M, Baumann K (2016) Type 1 diabetes: addressing the transition from pediatric to adult-oriented health care. Res Rep Endocr Disord 6:31-40. https://doi.org/10.2147/RRED.S56609

Mulvaney SA, Rothman RL, Wallston KA, Lybarger C, Dietrich MS (2010) An internet-based program to improve self-management in adolescents with type 1 diabetes. Diabetes Care 33(3):602-604. https://doi.org/10.2337/dc09-1881

Pyatak EA, Sequeira PA, Whittemore R, Vigen CP, Peters AL, Weigensberg MJ (2014) Challenges contributing to disrupted transition from paediatric to adult diabetes care in young adults with type 1 diabetes. Diabet Med 31(12):1615-1624. https://doi.org/10. 1111/dme.12485

Shulman R, Shah BR, Fu L, Chafe R, Guttmann A (2018) Diabetes transition care and adverse events: a population-based cohort study in Ontario. Canada Diabet Med 35(11):1515-1522. https://doi.org/ 10.1111/dme. 13782

Shulman R, Chafe R, Guttmann A (2019) Transition to adult diabetes care: a description of practice in the Ontario pediatric diabetes network. Can J Diabetes 43(4):283-289. https://doi.org/10.1016/j.jcjd. 2018.10.007

White M, O'Connell MA, Cameron FJ (2015) Transition to adult endocrine services: what is achievable? The diabetes perspective. Best Pract Res Clin Endocrinol Metab 29(3):497-504. https://doi.org/10. 1016/j.beem.2015.03.004

Publisher's note Springer Nature remains neutral with regard to jurisdictional claims in published maps and institutional affiliations. 